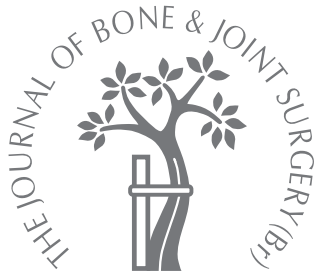

C. B. Hing,

D. A. Young,

R. E. Dalziel,

M. Bailey,

D. L. Back,

A. J. Shimmin

From the Melbourne Orthopaedic Group, Melbourne, Australia

C. B. Hing, MD, FRCS(Orth), Orthopaedic Fellow

D. A. Young, FAOrthA

Orthopaedic Surgeon

R. E. Dalziel, FAOrthA

Orthopaedic Surgeon

A. J. Shimmin, FAOrthA,

Orthopaedic Surgeon

Melbourne Orthopaedic Group

33 The Avenue, Windsor,

Victoria 3181, Australia.

M. Bailey, MSc, PhD,

Statistical Consultant

Department of Epidemiology and Preventive Medicine Monash University, The Alfred, Commercial Road, Melbourne, VIC 3004, Australia.

D. L. Back, FRCSEd(Ortho), Orthopaedic Surgeon

Guys and St Thomas Hospital, St Thomas Street, London SE1 9RT, UK.

Correspondence should be sent to Dr A. Shimmin; e-mail: ashimmin@optusnnet.com.au

(C)2007 British Editorial Society of Bone and Joint Surgery doi:10.1302/0301-620X.89B8. $18830 \$ 2.00$

$J$ Bone Joint Surg $[\mathrm{Br}]$ 2007;89-B:1019-24. Received 30 October 2006 Accepted after revision 6 March 2007

\title{
Narrowing of the neck in resurfacing arthroplasty of the hip
}

\author{
A RADIOLOGICAL STUDY
}

\begin{abstract}
Narrowing of the femoral neck after resurfacing arthroplasty of the hip has been described previously in both cemented and uncemented hip resurfacing. The natural history of narrowing of the femoral neck is unknown. We retrospectively measured the diameter of the femoral neck in a series of 163 Birmingham hip resurfacings in 163 patients up to a maximum of six years after operation to determine the extent and progression of narrowing.
\end{abstract}

There were 105 men and 58 women with a mean age of 52 years (18 to 82). At a mean follow-up of five years, the mean Harris hip score was 94.8 (47 to 100) and the mean flexion of the hip $112.5^{\circ}\left(80^{\circ}\right.$ to $\left.160^{\circ}\right)$. There was some narrowing of the femoral neck in $77 \%(125)$ of the patients reviewed, and in $27.6 \%$ (45) the narrowing exceeded $10 \%$ of the diameter of the neck. A multiple logistic regression analysis showed a significant association (chi-squared test (derived from logistic regression) $p=0.01$ ) of narrowing with female gender and a valgus femoral neck/shaft angle. There was no significant association between the range of movement, position or size of the component or radiological lucent lines and narrowing of the neck (chi-squared test; $p=0.10$ (flexion), $p=0.08$ (size of femoral component), $p=0.09$ (size of acetabular component), $p=0.71$ (femoral component angulation), $p=0.99$ (lucent lines)). There was no significant difference between the diameter of the neck at a mean of three years ( 2.5 to 3.5 ) and that at five years (4.5 to 5.5), indicating that any change in the diameter of the neck had stabilised by three years (sign rank test, $p=0.60$ ).

We conclude that narrowing of the femoral neck which is found with the Birmingham hip resurfacing arthroplasty is in most cases associated with no adverse clinical or radiological outcome up to a maximum of six years after the initial operation.

Proponents of hip resurfacing for the young, active patient emphasise the preservation of bone stock in the femoral head and neck as an advantage. ${ }^{1-3}$ Narrowing of the femoral neck has been noted as a sequel to hip resurfacing with no deleterious effect on outcome. ${ }^{3-5}$ One report has identified greater resorption of the femoral neck after the use of cemented femoral components in resurfacing arthroplasty than that with uncemented components. ${ }^{6}$ The natural history of narrowing after resurfacing arthroplasty has not been previously reported.

We undertook a retrospective analysis of prospectively acquired radiographs to investigate these changes at the femoral neck, and related them to clinical data.

\section{Patients and Methods}

Between April 1999 and June 2001, 230 Birmingham hip resurfacing (BHR) arthroplasties (Smith and Nephew-MMT, Birmingham, United Kingdom) were performed in 212 patients at our institution. The BHR has an acetabular component of cobalt chrome with a hydroxyapatite porous coating and a cemented femoral component. These patients have been reviewed prospectively over the ensuing years with standardised radiography and clinical examination.

From this group, we identified 163 consecutive patients with a maximum follow-up of six years having excluded 51 whose radiographs did not conform to the standardisation required.

Of the 163 patients, 16 (9.8\%) had undergone bilateral procedures, but since this number was too small to allow definitive repeat-measures analysis to be carried out, only the right hip from each of these patients was included in the study. There were 105 men and 58 women with resurfacing of 87 right and 76 left hips. Their mean age at the time of operation was 52 years (18 to 82 ). The pre-operative diagnosis included osteoarthritis (OA), 


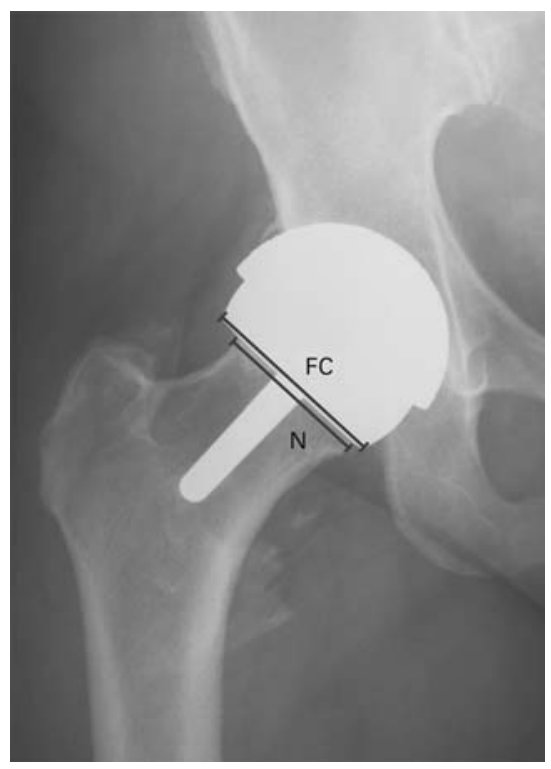

Fig. 1

Standardised anteroposterior radiograph showing measurement of the diameter of the femoral component (FC) and the neck (N).

avascular necrosis, rheumatoid arthritis (RA) and neurometabolic disorders. The mean follow-up time was five years (4 to 6). A total of 20 patients reached the sixth year. All patients were interviewed and the clinical outcome was assessed using the Harris hip score $(\mathrm{HHS})^{7}$ and the short form-12 score (SF-12), ${ }^{8}$ and the range of hip flexion was recorded using a goniometer. The patients' body mass index (BMI) was also calculated.

We retrospectively reviewed the radiographs taken in the immediate post-operative period at three and six months and at one year, and then annually thereafter to a maximum of six years after the operation. All the radiographs included in the study were standardised anteroposterior (AP) views of the pelvis and lateral views of the femoral neck at approximately $115 \%$, depending on body habitus. We assumed that any changes in the diameter of the neck would affect the coronal and sagittal planes equally, and therefore measurement of the diameter of the femoral neck was confined to the AP radiograph. We also assumed that there was no subsidence of the femoral component.

All the measurements were made by the principal investigator $(\mathrm{CBH})$ using a ruler. The diameter of the neck $(\mathrm{N})$ at the junction with the femoral component was divided by the diameter of the femoral component $(\mathrm{FC})$ producing a ratio (N/FC) to correct for any changes in magnification (Fig. 1). We used the junction of the neck and femoral component as the datum point since it was a fixed point on the radiographs. This measurement did not differentiate between narrowing confined to the femoral neck immediately adjacent to the implant or more distally in the neck. We defined narrowing of the femoral neck exceeding $10 \%$ as being significant. It was a requirement that the junction of the femoral component with the femoral neck projected radiologically as a straight line to satisfy the positional standardisation. Any radiograph not orientated in accordance with the standardised positioning was excluded from measurement.

Radiological assessment of radiolucent lines in the zones described by DeLee and Charnley ${ }^{9}$ around the acetabular component and in the zones described by Amstutz et $\mathrm{al}^{10}$ around the femoral component was used to produce a score. In addition, the angle of the femoral component with respect to that of the femoral neck to the femoral shaft and the acetabular abduction angle were also recorded ${ }^{3}$ (Fig. 2). A femoral component angle greater than the neck-shaft angle was considered to be valgus and that less than the neck-shaft angle was considered to be varus. Both the AP and lateral radiographs were also examined for the presence of cysts, notches and evidence of impingement.

The reliability of the measurements of the neck and the diameter of the femoral component was determined by repeating the radiological measurements by two observers $(\mathrm{CBH}, \mathrm{DAY})$ in a random sample of 20 on two separate occasions. An intraclass correlation coefficient (ICC) was used to calculate inter- and intraobserver reliability.

Statistical analysis. The patients' data were collected by independent observers ( $\mathrm{CBH}, \mathrm{DLB})$ using the Orthowave database Statware (Orthowave; Epinet, CRDa, Bruay, France). Statistical analysis was performed by an independent statistical consultant (BM) on anonymised data. Analysis was performed using SAS version 8.2 (SAS Institute Inc, Cary, North Carolina).

A univariate regression analysis was used for each patient to determine any change in the neck-to-femoralcomponent ratio with time. A logistic regression analysis was then used to compare the clinical and radiological findings in patients whose femoral narrowing exceeded $10 \%$, to the rest of the group. A multiple logistic regression was constructed using a stepwise selection procedure and validated using a backwards elimination procedure. Odds ratios with a $95 \%$ confidence interval $(\mathrm{CI})$ were used to express the change in risk associated with the predictor variable. A two-sided p-value $\leq 0.05$ was considered to be statistically significant.

Comparisons between years for neck diameter were perfomed using a Wilcoxon sign rank test. The relationship between the neck shaft angle, neck narrowing and gender was further explored using a two-way ANOVA, with an interaction term between gender and neck narrowing fitted to the model.

\section{Results}

The clinical details are summarised in Table I.

The reliability of the radiological measurements showed excellent agreement for intra- and interobserver measurements (intraclass correlation coefficient $>0.9$ ) of the diameters of femoral neck and the femoral compo- 


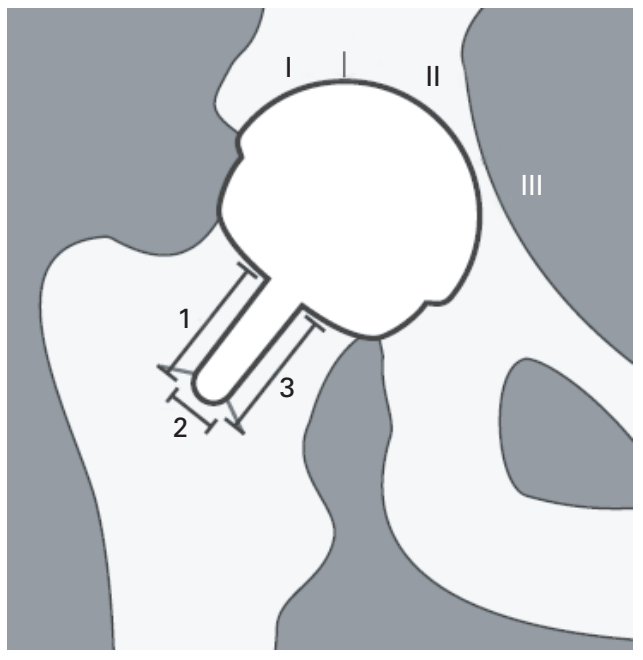

Fig. 2a

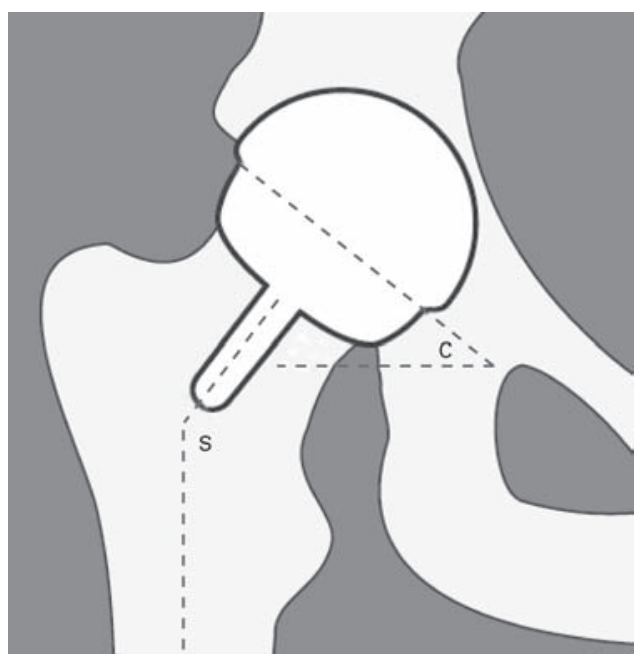

Fig. 2b

Diagrams showing a) the zones of DeLee and Charnley ${ }^{9}(\mathrm{I}, \mathrm{II}, \mathrm{III})$ and of Amstutz et $\mathrm{al}^{10}(1,2,3)$ and b) the neck-shaft angle (S) and acetabular abduction angle (C).

Table I. The mean (range) pre-operative and post-operative clinical details at a mean follow-up of five years (4 to 6 )

\begin{tabular}{llr}
\hline & Pre-operative & Post-operative \\
\hline Harris hip score & 64.0 (8 to 98$)$ & 94.8 (47 to 100$)$ \\
SF-12 ${ }^{8}$ physical & $31.2(18.1$ to 42.6$)$ & 52.3 (27.3 to 63.0$)$ \\
SF-12 ${ }^{8}$ mental & $58.2(33.3$ to 71.0$)$ & 55.3 (21.6 to 65.8$)$ \\
Flexion $\left(^{\circ}\right)$ & $91.2(-25$ to 140$)$ & 112.5 (80 to 160$)$
\end{tabular}

nent. A univariate analysis compared changes in the N/FC ratio with time. Of the 163 hips in 163 patients, 125 $(77 \%)$ had a negative regression slope indicating that the diameter of the femoral neck had reduced with time. There was no significant difference between the neck diameter (Wilcoxon sign rank test, $\mathrm{p}=0.60$ ) at a mean of three years (44 mm, 33 to 60 ) and that at five years ( $44 \mathrm{~mm}, 27$ to 60$)$ indicating that any change in neck diameter had stabilised by three years.

Of the 163 hips, $45(27.6 \%)$ showed a reduction of more than $10 \%$ in the width of the femoral neck (Fig. 3). A logistic regression analysis comparing those hips with this change with those without any narrowing of the femoral neck showed an association with the anatomical neck-shaft angle and gender. There was a significant difference (chi-squared test, $p=0.01$ ) in the narrowing found according to the angulation of the femoral neck to the shaft with a valgus femoral neck being associated with narrowing. With every one degree unit increase in a valgus direction of the femoral neck/shaft angulation, the risk of developing narrowing of the neck of more than $10 \%$ increased by $9 \%(\mathrm{OR}=1.09 ; 95 \%$ CI 1.02 to 1.16 , chisquare test, $\mathrm{p}=0.007)$. Gender was found to be more important than BMI as a risk factor for narrowing, with women being 2.5 times more likely than men to develop narrowing exceeding $10 \%(\mathrm{OR}=2.5 ; 95 \%$ CI 1.2 to 5.2 ; chi-squared test, $\mathrm{p}=0.01)$. Analysis of the relationship of gender and the anatomical angulation of the femoral neck showed that this angulation was significantly greater in all the women studied (mean $139.0^{\circ}\left(120^{\circ}\right.$ to $\left.154^{\circ}\right)$ compared with men (mean $136.0^{\circ}\left(118^{\circ}\right.$ to $\left.150^{\circ}\right)$; F-test (derived from two-way ANOVA), $\mathrm{p}=0.0001)$. The mean neck/ shaft angle was $139.1^{\circ}\left(122^{\circ}\right.$ to $\left.154^{\circ}\right)$ in women with neck narrowing greater than $10 \%$, and $136.6^{\circ}\left(120^{\circ}\right.$ to $154^{\circ}$ ); in those with narrowing of less than $10 \%$ (Ftest, $\mathrm{p}=0.99$ ) indicating that gender was more important than angulation for predicting narrowing of the femoral neck.

A small size of component had an association with narrowing of the femoral neck but this was not statistically significant (femoral component $\mathrm{OR}=0.93$ (0.86 to 1.01); $95 \%$ CI 0.86 to 1.01 , chi-squared test, $\mathrm{p}=0.08$; acetabular component, $\mathrm{OR}=0.93,95 \%$ CI 0.85 to 1.01 , chi-squared test, $\mathrm{p}=0.09$ ). Patient outcome scores, radiologically identified notching, activity levels, and the position of the component, had no statistical association with the development of narrowing of the femoral neck of greater than $10 \%$. These results are summarised in Table II. 


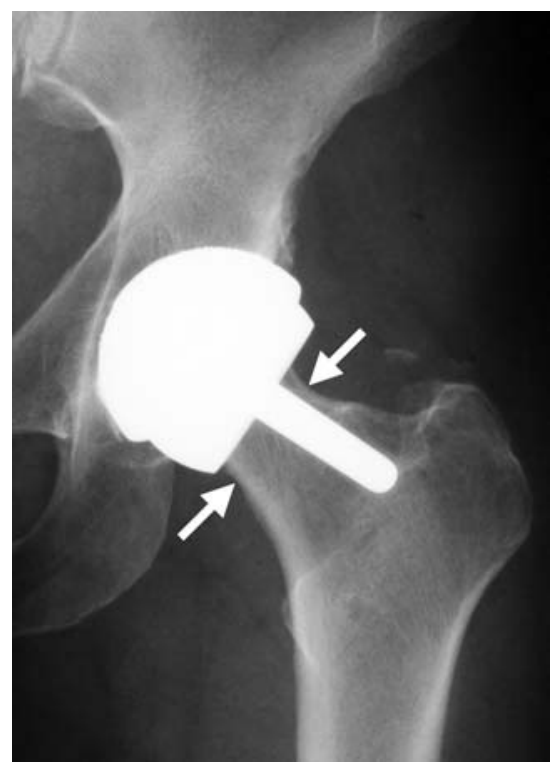

Fig. 3a

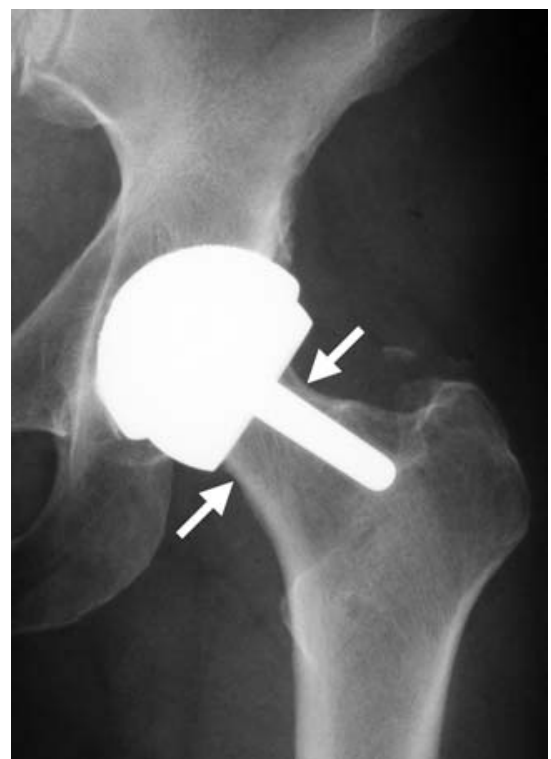

Fig. 3b
Anteroposterior radiographs of a 60 -year-old woman with osteoarthritis a) four years postoperatively who had the femoral component inserted in varus and b) at four years, the component was radiologically stable but the femoral neck was narrowed $17 \%$ from its original diameter.

Table II. Measurements (mean, range) at a mean follow-up of five years in hips with narrowing of more than $10 \%$ and those with narrowing of less than $10 \%$

\begin{tabular}{|c|c|c|c|}
\hline & \multicolumn{2}{|l|}{ Narrowing } & \multirow[b]{2}{*}{ p-value } \\
\hline & $\geq 10 \%$ & $<10 \%$ & \\
\hline Body mass index $\left(\mathrm{kg} / \mathrm{m}^{2}\right)$ & $26.4(16.2$ to 42.8$)$ & 27.7 (20.1 to 45.3 ) & 0.10 \\
\hline Flexion $\left({ }^{\circ}\right)$ & $115.0(90$ to 160$)$ & $111.5(80$ to 140$)$ & 0.10 \\
\hline Harris hip score ${ }^{\dagger}$ & $95.1(47$ to 100$)$ & 94.6 (63 to 100$)$ & 0.74 \\
\hline Anatomical femoral neck-shaft angle $\left({ }^{\circ}\right)$ & $140.0(122$ to 154$)$ & 136.5 (118 to 150$)$ & 0.002 \\
\hline Femoral component size $(\mathrm{mm})$ & $48 \quad$ (42 to 58$)$ & $50 \quad$ (38 to 58$)$ & 0.08 \\
\hline Acetabular component size (mm) & $54 \quad$ (48 to 66$)$ & $56 \quad(46$ to 64$)$ & 0.09 \\
\hline Femoral component angulation $\left({ }^{\circ}\right)$ & $136.6(125$ to 154$)$ & $136.6(120$ to 158$)$ & 0.71 \\
\hline
\end{tabular}

\section{Discussion}

Narrowing of the femoral neck has been reported in cemented hip resurfacing in less than $10 \%$ of cases, but its natural history is unknown. ${ }^{3-6}$ This change has not been associated with an increasing risk of fracture of the femoral neck, functional impairment or failure in the short term. ${ }^{3-5}$ The aetiology of narrowing is also unknown. It may be the result of a vascular insult to the femoral head and neck, impingement, stress shielding and remodelling or an inflammatory response to wear particles.

The blood supply to the femoral head and neck in OA is controversial. Notching of the femoral neck during resurfacing arthroplasty has been shown to cause a reduction in blood flow of $50 \% .{ }^{11}$ Removal of the retinaculum may also affect the blood supply to the femoral head and neck increasing the risk of osteonecrosis. ${ }^{11}$ Earlier studies have hypothesised that the main blood supply to the femoral head is intraosseous, but more recent studies have shown that the retinacular vessels provide a significant blood supply in OA. ${ }^{11,12}$ The surgical approach has also been shown to cause a decrease in oxygen concentration to the head of $60 \%$ with a further drop of $20 \%$ on insertion of the component indicating that damage to the blood supply may have occurred. ${ }^{13}$ Retrieval studies of femoral heads in failed femoral resurfacing have shown evidence of osteonecrosis which may play a part in fracture and failure of the neck. ${ }^{14}$

In our study, all three of the surgeons (AJS, DAY, RED) used a standard posterior approach and operating technique. It is conceivable that disruption of the deep branch of the medial circumflex artery may have affected the blood supply to the femoral head and neck and contributed to the narrowing of the neck. We found no association between the occurrence of a notch in the superior aspect of the femoral neck and subsequent narrowing.

We measured the diameter of the neck using the femoral component-neck junction as the datum point. We found narrowing of more than $10 \%$ in $27.6 \%$ (45) of the hips studied which was more than that reported by Amstutz et $\mathrm{al}^{10}$ with the Conserve Plus resurfacing prosthesis (Wright Medical Technology, Arlington, Tennessee) (< $10 \%$ ), but similar to the incidence of $27 \%$ identified by Lilikakis, Vowler and Villar ${ }^{15}$ with the uncemented Cormet 
2000 device (Corin Medical, Cirencester, United Kingdom). We assumed that there was no subsidence of the femoral component over time. This assumption was reasonable based on the fact that the stability of the BHR at two years has been confirmed in a radiostereophotogrammetric analysis. ${ }^{16}$ We only examined narrowing of the neck in the AP plane, assuming that any reduction in the diameter of the femoral neck would occur equally in all planes. Therefore we did not measure the diameter on lateral radiographs. This was a limitation of our study and examination by CT would improve the accuracy of this measurement.

The narrowing of the femoral neck exceeding $10 \%$ of its diameter had stabilised by a mean of three years with no significant difference in the diameter between three and five years post-operatively. Previous studies have shown a significant increase in the incidence of narrowing of the femoral neck when comparing cemented resurfacing (BHR) with uncemented resurfacing (Cormet). ${ }^{6,15}$ This may indicate that cement is implicated in the narrowing of the neck, but it is important to note that the implants used may not have been comparable. The hydroxyapatite (HA) coating of the Cormet femoral implant may result in a different loading pattern to that of the BHR. Lilikakis et $\mathrm{al}^{15}$ found that $27 \%$ of the Cormet implants studied showed narrowing confined to the lower aspect of the neck. In our study, the two patients who had the most femoral narrowing had a greater loss of bone stock in the superolateral as opposed to the inferomedial aspect of the neck. While this contrasts with the findings of Lilikakis et $\mathrm{al}^{15}$ it is in keeping with the results of other canine and human studies which have shown stress shielding of the upper cortex and loading of the lower cortex resulting in a thinner upper cortex and a thicker lower cortex. ${ }^{17-21}$

Finite-element analysis of the BHR with three-dimensional (3D) models based on cadavers and including both acetabular and femoral components assigning anisotropic properties to the trabecular bone have shown superolateral stress shielding with stress transfer to the medial cortex. ${ }^{22-24}$ Reduction of strain in the inferomedial and superolateral cortices has also been shown. ${ }^{22-24}$ These models have also predicted initial bone resorption specifically at the headneck junction. While bone remodelling is a feature of normal metabolism in healthy bone as well as in that with OA, the BHR may result in stress shielding with resorption and narrowing of the femoral neck resulting from altered load conditions, explaining the presence of narrowing found in our study. Finite-element analysis depends on its accuracy on the properties assigned to the model which must consider anisotropy of bone, the effect of OA on bone remodelling, the presence of the pelvis and the femoral and acetabular components, the size and orientation of the components and the dynamic nature of the situation modelled. In addition, bone density is affected by age and gender. Our results agree with those of other studies indicating that stress shielding occurs with remodelling in the first three years after implantation. Whether this stabilises as suggested in our study or continues with changes in bone turnover requires further investigation.

We performed a logistic regression analysis to determine the association of narrowing of the femoral neck with clinical and radiological findings. This identified a significant association between narrowing and female gender and an anatomical valgus femoral neck-shaft angle. There was also a trend for a smaller size of component to be associated with narrowing, but this did not reach statistical significance. Amstutz et $\mathrm{al}^{10}$ also showed an association between height, female gender, smaller size of component and failure of the femoral component. However, the mechanism of failure of the femoral component may not be the same as the cause of narrowing of the femoral neck and we found no association between the Amstutz scores used to record the presence of radiolucent lines around the peg of the femoral component, and neck narrowing. Furthermore our patients with narrowing of the femoral neck which exceeded $10 \%$ had a higher HHS indicating no deleterious effect of narrowing on clinical outcome. We agree with Amstutz et $\mathrm{al}^{10}$ that female gender, a smaller size of component and a low BMI were associated with narrowing, but only gender was statistically significant in our study, which may indicate that other factors specific to bone metabolism in the female, such as hormonal status, may be important in predicting susceptibility to narrowing of the femoral neck.

We found that an anatomically valgus femoral neck and a femoral component placed with a varus orientation were associated with narrowing of the femoral neck (Fig. 3) although statistical significance was not reached for the association of narrowing and orientation of the femoral component (linear regression, $\mathrm{p}=0.52$ ). Varus component placement has also been associated with femoral fracture and failure of the implant. ${ }^{4,5,10}$ This may indicate that altered loading of the femoral neck results in fracture or loosening but we did not find any association between narrowing of the neck and the presence of lucent lines. Furthermore, most of our patients had a valgus femoral neck which may have skewed the results. Further analysis showed that a higher neck-shaft angle was present in women overall, with no difference in the neck-shaft angle in those women who had developed post-operative narrowing of the femoral neck. This implies that gender, rather than BMI or neckshaft angle, is the most important factor in predicting subjects at risk of developing narrowing.

There was a weak trend (linear regression, $\mathrm{p}=0.28$ ) towards an association between a high HHS and narrowing, suggesting that higher activity levels may be associated with changes in the diameter and density of the neck because of remodelling or changes in vascularity of the head and neck. However, no association was found between the SF-12 score or the flexion angle and narrowing of the femoral neck which would have been expected if there was a significant association with the HHS.

In conclusion, we found that post-operative narrowing of the femoral neck occurred in a significant proportion of 
BHRs and stabilised by three years. It was not associated with a deleterious clinical outcome at a maximum followup of six years. Narrowing of the neck appears to be a common phenomenon with the BHR, but further study is required to determine if it is clinically significant in the long term. It remains to be seen whether patients with narrowing of the femoral neck in excess of $10 \%$ will be more susceptible to fracture of the neck since the metabolism of the bone alters with advancing age, and whether menopausal status in women also has an effect on the risk of fracture of the femoral neck.

We acknowledge the help of G. Zimmerman, M. Walker, D. Liu, D. Wood and L. Vivian with collection of the data.

No benefits in any form have been received or will be received from a commercial party related directly or indirectly to the subject of this article.

\section{References}

1. Treacy RBC, McBryde CW, Pynsent PB. Birmingham hip resurfacing arthroplasty. J Bone Joint Surg [Br] 2005;87-B:167-70.

2. Daniel J, Pynsent PB, McMinn DJW. Metal-on-metal resurfacing of the hip in patients under the age of 55 years with osteonecrosis. J Bone Joint Surg [Br]2004;86B:177-84

3. Back DL, Dalziel R, Young D, Shimmin A. Early results of primary Birmingham hip resurfacings. J Bone Joint Surg [Br] 2005;87-B:324-9.

4. Shimmin AJ, Back DL. Femoral neck fractures associated with hip resurfacing: a national review of 50 cases. J Bone Joint Surg [Br] 2005;87-B:463-4.

5. Cossey AJ, Back DL, Shimmin A, Young D, Spriggins AJ. The non-operative management of periprosthetic fractures associated with the Birmingham hip. $J$ Arthroplasty 2005;20:358-61.

6. Katrana P, Crawford JR, Vowler S, Lilikakis A, Villar RN. Femoral neck resorption after hip resurfacing arthroplasty: a comparison of cemented and uncemented prostheses. J Bone Joint Surg [Br] 2006;88-B(Suppl II):234.

7. Harris WH. Traumatic arthritis of the hip after dislocation and acetabular fractures: treatment by mold arthroplasty: an end result study using a new method of result evaluation. J Bone Joint Surg [Am] 1969;51-A:737-55.
8. Dawson J, Fitzpatrick R, Murray D, Carr A. Comparison of measures to assess outcomes in total hip replacements. Qual Health Care 1996;5:81-8.

9. DeLee JG, Charnley J. Radiological demarcation of cemented sockets in total hip replacement. Clin Orthop 1976;121:20-32.

10. Amstutz HC, Beaulé PE, Dorey FJ, et al. Metal-on-metal hybrid surface arthroplasty: two to six-year follow-up study. J Bone Joint Surg [Am] 2004;86-A:28-39.

11. Beaulé PE, Campbell PA, Hoke R, Dorey F. Notching of the femoral neck during resurfacing arthroplasty of the hip: a vascular study. J Bone Joint Surg [Br] 2006;88B:35-9.

12. Freeman MAR. Some anatomical and mechanical considerations relevant to the surface replacement of the femoral head. Clin Orthop 1978;13:19-24.

13. Steffen RT, Smith SR, Urban JPG, et al. The effect of hip resurfacing on oxygen concentration in the femoral head. J Bone Joint Surg [Br]2005;87-B:1468-74.

14. Little CP, Ruiz AL, Harding IJ, et al. Osteonecrosis in retrieved femoral heads after failed resurfacing arthroplasty of the hip. J Bone Joint Surg [Br]2005;87-B:320-30.

15. Lilikakis AK, Vowler SL, Villar RN. Hydroxyapatite-coated femoral implant in metal-on-metal resurfacing hip arthroplasty: minimum of two years follow-up. Orthop Clin North Am 2005;36:215-22.

16. Itayem R, Arndt A, Nistor L, McMinn D, Lundberg A. Stability of the Birmingham hip resurfacing arthroplasty at two years. J Bone Joint Surg [Br] 2005;87-B:158-62.

17. Watanabe Y, Shiba N, Matsuo S, et al. Biomechanical study of the resurfacing hip arthroplasty. J Arthroplasty 2000;15:505-11.

18. Kishida Y, Sugano N, Nishiii T, et al. Preservation of the bone mineral density of the femur after surface replacement of the hip. J Bone Joint Surg [Br]2004;86-B:1859.

19. De Waal Malefijt MC, Huiskes R. A clinical, radiological and biomechanical study of the TARA hip prosthesis. Arch Orthop Trauma Surg 1993;112:220-5.

20. Hedley A, Moreland JR, Bloebaum R, et al. Press-fit, cemented, and bone ingrowth surface replacement: canine fixation model. Proc Annual Meeting of the Orthopaedic Research Society. 1979:163.

21. Hedley A, Clarke IC, Bloebaum R, et al. Viability and cement fixation of the femoral head in canine hip surface replacement. The Hip. Proceedings of the Hip Society. St Louis: CV Mosby 1979:160-87.

22. Ong KL, Kurtz SM, Manley MT, et al. Biomechanics of the Birmingham hip resurfacing arthroplasty. J Bone Joint Surg [Br] 2006;88-B:1110-15.

23. Gupta S, New AM, Taylor M. Bone remodelling inside a cemented resurfaced femoral head. Clin Biomech 2006;21:594-602.

24. Taylor M. Finite element analysis of the resurfaced femoral head. Proc Inst Mech Eng [H] 2006;220:289-97. 